\title{
A High Spatial Resolution MEA for Voltammetric Analysis of Trace Metals in Water Pollution Based on Partial Least Squares Regression
}

\author{
Hui Xin Zhao ${ }^{1}$, Wei Cai ${ }^{1}$, Hao Wan ${ }^{1}$, Da Ha ${ }^{1}$ and Ping Wang ${ }^{1 *}$ \\ ${ }^{1}$ Biosensor National Special Laboratory, Key Laboratory for Biomedical Engineering of Education \\ Ministry, Department of Biomedical Engineering, Zhejiang University, Hangzhou, China \\ "Corresponding author: cnpwang@zju.edu.cn
}

\begin{abstract}
:
Estimation of heavy metals in water has been paid significant attention because of the toxicity of such metals on the whole ecological system. A microelectrode array (MEA) of individually addressable microelectrodes was fabricated for cadmium, lead and copper analysis in water pollution. The ratio of interelectrode distance to the electrode diameter of the MEA was sufficient enough to get a collective current response while maintaining the excellent features of single microelectrodes. Cyclic voltammograms made in various scan rates confirmed that a high spatial resolution MEA was constructed with no diffusion layers overlapping. Then the mercury film Au-MEA was utilized to detect cadmium, lead and copper ions using differential pulse anodic stripping voltammetry (DPASV). The sensitivity of $130 \mathrm{nA} / \mu \mathrm{g}, 52 \mathrm{nA} / \mu \mathrm{g}$ and $46 \mathrm{nA} / \mu \mathrm{g}$ for $\mathrm{Cd}^{2+}, \mathrm{Pb}^{2+}$ and $\mathrm{Cu}^{2+}$ ions, separately, were achieved using this microsensing chip. Calibrations were made via partial least-squares regression (PLSR) modeling. Well correlation was found between the lab-determined values and the values predicted from PLSR calibration.
\end{abstract}

Key words: Water pollution, heavy metals detection, microelectrode array (MEA) chips, partial least squares regression (PLSR).

\begin{abstract}
Introduction
Heavy metals have a widespread distribution within natural water environment. Because of the toxicity of such metals on the whole ecological system, even at low concentrations $\left(10^{-7}-10^{-11} \mathrm{M}\right)$, heavy metals ingestion may induces health problems [1, 2]. Electrochemical sensors are the most useful techniques for trace heavy metals detection due to their sensitivity, selectivity, fast and simultaneously measurement of various elements. Modified electrodes by some materials such as noble metal bismuth can be used for direct detection of heavy metals since the latest decades [3]. However, the oxidation voltage of bismuth was not high enough which lead to the narrow detection voltage window of the bismuthcovered electrodes. For instance, copper analysis was not available using bismuthcovered electrodes since the stripping voltage of bismuth was lower than that of copper. Mercury is regarded as the most sensitive material for heavy metals detection and at the same time, multi-elements such as cadmium, lead and copper can be determined simultaneously by the mercury-covered electrodes. The rapid development of
\end{abstract}

microfabrication has paved the way for the application of microelectrodes in the electrochemical studies and applications. They offer a number of advantages when employed in the assay of trace metals such as enhanced mass transport rate, high signal to noise ratio, low ohmic drop of the analyte solution, etc. MEA is a composite microelectrode array which improves the amperometric current response. However, unlike single microelectrodes, for MEA, the geometry must be considered to avoid shield effect [4]. That is, the ratio of interelectrode distance (center to center, $w$ ) to the electrode dimension (e.g., electrode diameter for disc microelectrodes, $d$ ) must be sufficient enough to get a collective current response while maintaining the excellent electrochemical properties of single microelectrodes.

The aim of this paper is to fabricate a high spatial resolution MEA with sufficient interelectrode distance, which was employed for trace heavy metals cadmium, lead and copper ions detection in water pollution modified with mercury film. In addition, 
calibrations were made via PLSR modeling to minimize multicollinearity of the detection data.

\section{Experimental}

\section{Fabrication of MEA Chip}

The gold MEA chip was prepared based on MEMS technology. The substrate was 4-inch Corning 7740 Pyrex glass, a layer of gold (250nm thickness) was sputtered after a chromium adhesion layer (100nm) deposited. Then the photoresist was spun and patterned. At last, the insulating layer $\mathrm{SiO}_{2} / \mathrm{Si}_{3} \mathrm{~N}_{4} / \mathrm{SiO}_{2}$ (100nm/300nm/100nm) was deposited by plasma enhanced chemical vapor deposition (PECVD) technology. Following fabrication, the wafers were diced and the electrode arrays were packaged on printed circuit boards (PCB) with silver epoxy. The schematic diagrams and photos of the fabricated MEA chip are shown in Fig. 1. The whole size of the Au-MEA chip was $1.04 \times 1.04 \mathrm{~cm}^{2}$, consisted of $6 \times 6$ individually addressable microelectrodes, with the single electrode diameter $30 \mu \mathrm{m}$ separated by a $300 \mu \mathrm{m}$ gap.

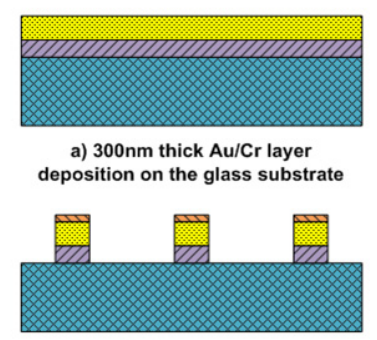

b) $\mathrm{Au} / \mathrm{Cr}$ layer patterning

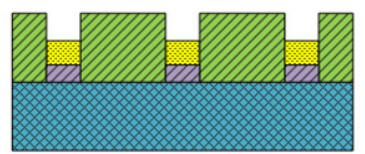

$\mathrm{SiO}_{2} / \mathrm{Si}_{3} \mathrm{~N}_{4} / \mathrm{SiO}_{2}$ deposition and patterning

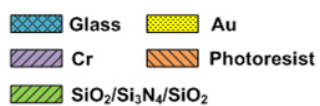

(a)

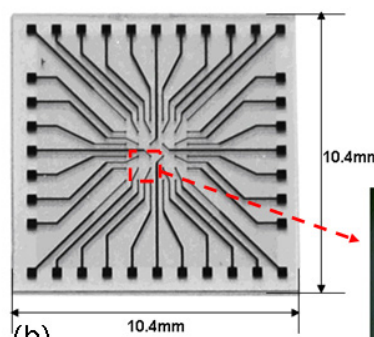

(b)

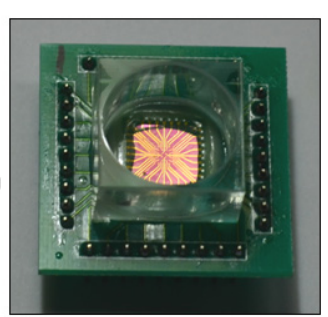

(c)

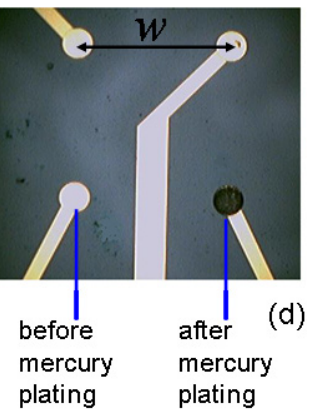

Fig. 1. Schematic structure of the Au-MEA chip (a) fabrication process of the Au-MEA chip, (b) photo of the chip after diced, (c) photo of the MEA chip after encapsulation and (d) optical micrograph of the Au microelectrodes before and after mercury plating $(w=300 \mu m)$.

\section{Electrodepositon of Mercury Film}

A CHI660 electrochemical analyser was used for all electrochemical studies. All experiments were performed in a three-electrode cell, where the working electrode was the Au-MEA chip, and the counter electrode was a platinum wire electrode, with a saturated calomel electrode (SCE) as the reference electrode. Mercury film was modified on the surface of the Au-MEA by chronoamperometry deposition method at the potential of $0.1 \mathrm{~V}$ (vs. SCE) in $6 \times 10^{-4} \mathrm{M} \mathrm{Hg}\left(\mathrm{NO}_{3}\right)_{2}$ solution with the deposition time of 60 s.

\section{Results and Discussion}

\section{Surface Modification Analysis}

It was found that the surface of the Au-MEA modified by chronoamperometry deposition of mercury had changed to dark (Fig.1d). The amount of deposited mercury for each individual microelectrode was calculated as $2.1 \times 10^{-11} \mathrm{M}$. So the recontamination problem caused by the mercury film may be negligible.

\section{Characterization of the Working MEA}

It has been confirmed that the spacing distance between the adjacent microelectrodes strongly influences the diffusion process of the redox reactions. The ratio of the spacing distance $(w)$ to the electrode dimension (e.g., electrode diameter for disc microelectrodes, $d$ ) must be sufficient enough to avoid shield effect. In this paper, the ratio $w / d$ of the MEA was designed to be $10: 1$.

The Au-MEA was characterized by cyclic voltammetry in $2 \mathrm{mM} \mathrm{K}_{3}\left[\mathrm{Fe}(\mathrm{CN})_{6}\right]$ dissolved in $1 \mathrm{M} \mathrm{KCl}$ solution at various scan rates $v$ ranging from $10 \mathrm{mV} / \mathrm{s}$ to $100 \mathrm{mV} / \mathrm{s}$ (Fig.2). The response voltammograms were all sigmoidal shape that can be related to disc microelectrode behavior (spherical diffusion). For $v=10 \mathrm{mV} / \mathrm{s}$ and 20 $\mathrm{mV} / \mathrm{s}$, the limiting currents showed steady states, and for $v=50 \mathrm{mV} / \mathrm{s}$ and $100 \mathrm{mV} / \mathrm{s}$, the curves showed quasisteady states. This was in accordance with the concentration profiles of ferricyanide calculated at the switching potential. 
The lengths of diffusion layers can be calculated from eq. (1).

$$
\delta=2(D t)^{1 / 2}
$$

where $D$ is the diffusion coefficient of ferricyanide $\left(0.76 \times 10^{-5} \mathrm{~cm}^{2} / \mathrm{s}\right)$, time $t$ was estimated from the scan rate and the potential range between the point where the surface concentration of the reacting species has dropped to zero and the switching potential. The potential range was ca.0.6V in this paper. For each scan rate, the lengths of diffusion layers are calculated as $42.7 \mu \mathrm{m}, 30.2 \mu \mathrm{m}, 19.1 \mu \mathrm{m}$ and $13.5 \mu \mathrm{m}$, provides a measure of how far the concentration has propagated in the $\mathrm{x}$-direction by diffusion in time $t$, though this equation is only valid for 1-dimensional diffusion, it provides a rough approximation of the expansion of the diffusion zones around the microelectrodes during a voltammetric experiment [5]. It is apparent that, for $v=10 \mathrm{mV} / \mathrm{s}$ and $20 \mathrm{mV} / \mathrm{s}$, the diffusion lengths were not smaller than the diameter of the microelectrode $(30 \mu \mathrm{m})$ and it was opposite for $v=50 \mathrm{mV} / \mathrm{s}$ and $100 \mathrm{mV} / \mathrm{s}$. This may be the reason for the quasisteady states for $v=50 \mathrm{mV} / \mathrm{s}$ and $100 \mathrm{mV} / \mathrm{s}$. But the diffusion zones did not overlap with the adjacent microelectrodes for all scan rates (the diffusion lengths were all smaller than the interelectrode distance of $300 \mu \mathrm{m}$ ), confirming that a high spatial resolution MEA was constructed.

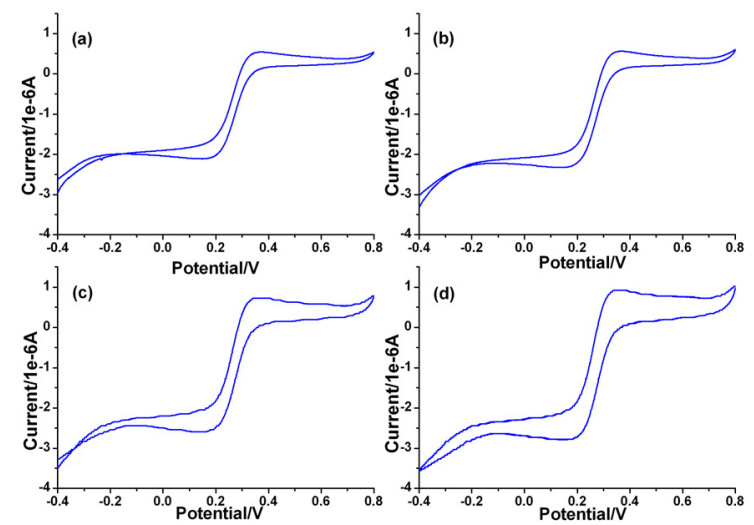

Fig. 2. Cyclic voltammograms of Au-MEA in $2 \mathrm{mM}$ $\mathrm{K}_{3}\left[\mathrm{Fe}(\mathrm{CN})_{6}\right]$ dissolved in $1 \mathrm{M} \mathrm{KCl}$ solution at a) $10 \mathrm{mV} / \mathrm{s}$, b) $20 \mathrm{mV} / \mathrm{s}$, c) $50 \mathrm{mV} / \mathrm{s}$ and d) $100 \mathrm{mV} / \mathrm{s}$ ( $\mathrm{vs}$. SCE).

In addition, the limited diffusion current for the microdisk electrode array is

$$
I=4 m n F D r c_{0}
$$

where $m$ is the number of the microelectrode, $n$ is the number of electrons transferred, $r$ is the radius of the microelectrode and $c_{0}$ is the bulk concentration of the ferricyanide. In this paper, the ratio of the experimental steady state current and the theoretical value (eq.2) is close to unity. This also indicates typical behaviour of the inlaid microdisc array having no overlap of diffusion fields as already mentioned [6].

\section{Analysis of Cadmium, Lead and Copper in Water and PLSR Calibration}

The mercury film Au-MEA was employed to detect $\mathrm{Cd}^{2+}, \mathrm{Pb}^{2+}$ and $\mathrm{Cu}^{2+}$ ions using DPASV in artificial water samples (Fig.3a). The $\mathrm{pH}$ values of the samples were all adjusted to about 4.0 and $0.5 \mathrm{M} \mathrm{KCl}$ solution was used as the supporting electrolyte. The deposition potential was $-1.0 \mathrm{~V}$ with the deposition time of $120 \mathrm{~s}$. It can be seen that, $\mathrm{Cd}^{2+}, \mathrm{Pb}^{2+}$ and $\mathrm{Cu}^{2+}$ ions can be easily separated from each other in the voltammograms and the stripping peaks of the three ions were relatively stable and sharp. The concentration linearity of $\mathrm{Cd}^{2+}, \mathrm{Pb}^{2+}$ and $\mathrm{Cu}^{2+}$ were well with the calibration curve correlation coefficient all close to 0.90 . The sensitivity of 130nA/ $\mu \mathrm{g}, 52 \mathrm{nA} / \mu \mathrm{g}$ and $46 \mathrm{nA} / \mu \mathrm{g}$ for $\mathrm{Cd}^{2+}, \mathrm{Pb}^{2+}$ and $\mathrm{Cu}^{2+}$, separately, were obtained using this microsensing chip.

Tab. 1: The concentrations of $\mathrm{Cd}, \mathrm{Pb}$ and $\mathrm{Cu}$ ions of training data, unit $\left(\mu g \cdot L^{-1}\right)$

\begin{tabular}{|c|c|c|c|}
\hline No. & $\mathrm{Cd}$ & $\mathrm{Pb}$ & $\mathrm{Cu}$ \\
\hline 1 & 2 & 10 & 10 \\
\hline 2 & 6 & 30 & 30 \\
\hline 3 & 10 & 50 & 50 \\
\hline 4 & 2 & 30 & 50 \\
\hline 5 & 6 & 50 & 10 \\
\hline 6 & 10 & 10 & 30 \\
\hline 7 & 2 & 50 & 30 \\
\hline 8 & 6 & 10 & 50 \\
\hline 9 & 10 & 30 & 10 \\
\hline
\end{tabular}

Tab. 2: The concentrations of $\mathrm{Cd}, \mathrm{Pb}$ and $\mathrm{Cu}$ ions of verification data, unit $\left(\mu \mathrm{g} . \mathrm{L}^{-1}\right)$

\begin{tabular}{|c|c|c|c|}
\hline No. & $\mathrm{Cd}$ & $\mathrm{Pb}$ & $\mathrm{Cu}$ \\
\hline 1 & 4 & 20 & 20 \\
\hline 2 & 8 & 40 & 40 \\
\hline
\end{tabular}

According to the Nernst-Planck equation, the corresponding stripping current of each heavy metal is linear with its concentration. The peak amplitudes were always used as the calibration data which may ignore the interrelationship between the ions and the multicollinearity of each heavy metal's stripping currents. In contrast, PLSR performs the regression using 
full-spectrum data. The training samples 1-9 (Fig.3a) were used to derive the PLSR algorithm and the verification samples 1 and 2 (Fig.3a) assessed the model's predictive ability. The concentrations of $\mathrm{Cd}, \mathrm{Pb}$ and $\mathrm{Cu}$ ions of training data and verification data were shown in Tab.1 and Tab.2, separately. It can be seen in Fig.3b that well correlation can be found between the lab-determined values and the values predicted from PLSR calibration for $\mathrm{Cd}^{2+}, \mathrm{Pb}^{2+}$ and $\mathrm{Cu}^{2+}$ ions.
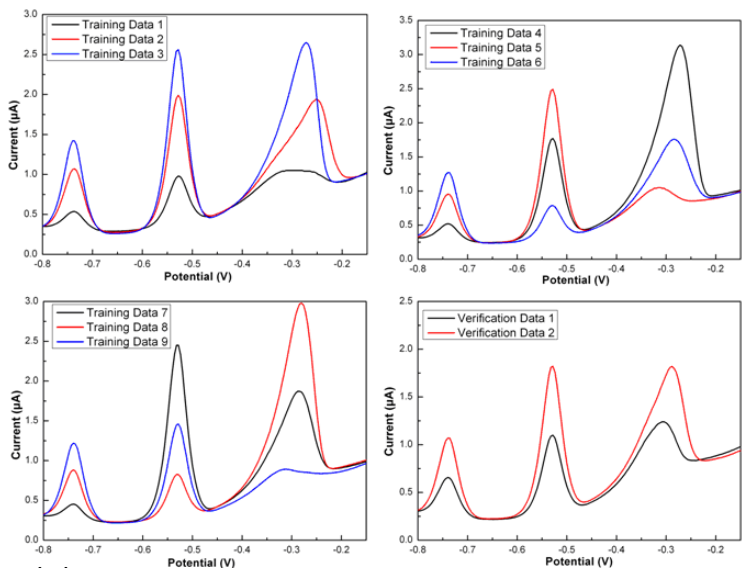

(a)

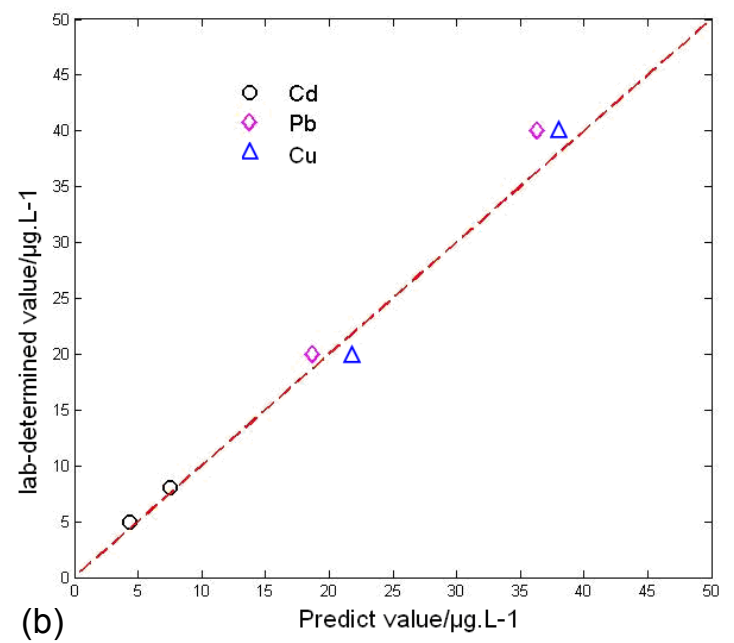

Fig. 3. (a) Stripping voltammograms of Cd (left peaks), $\mathrm{Pb}$ (middle peaks) and $\mathrm{Cu}$ (right peaks) ions in $0.5 \mathrm{M} \mathrm{KCl}$ solution (vs.SCE), and (b) the predict values of PLSR compared to the lab-determined values.

\section{Conclusions}

A high spatial resolution Au-MEA consists of 36 individually addressable microelectrodes was proposed and fabricated for trace heavy metals detection in water pollution. The ratio of interelectrode distance of microelectrode diameter was 10:1, which was confirmed sufficient enough to get a collective current response while maintaining the spherical diffusion behavior of single microelectrodes. The array was prepared successfully using microfabrication technology. The mercury covered Au-MEA was available for detection of heavy metals $\mathrm{Cd}^{2+}, \mathrm{Pb}^{2+}$ and $\mathrm{Cu}^{2+}$, where calibration was performed by PLSR with well correlation coefficient. The recontamination problem caused by mercury was negligible because of the amount of deposited mercury was little (about $2.1 \times 10^{-11} \mathrm{M}$ ).

\section{Acknowledgements}

This work has been supported by grants from the National Basic Research Program of China (973 program). Grant No. 2009CB320303.

\section{References}

[1] H.X.Zhao, W.Cai, D.Ha, H.S.Guo, P.Wang, The Characterization of a Double-Side Nanoband Electrode Array and its Application to Heavy Metals Detection, Sensors Letters 9(2), 801-806 (2011); doi: 10.1166/sl.2011.1618

[2] H.X.Zhao, W.Cai, D.Ha, H.Wan, P.Wang, The Study on Novel Microelectrode Array Chips for the Detection of Heavy Metals in Water Pollution, Journal of Innovative Optical Health Sciences 5(1), (2012); doi: 10.1142/S1793545811500027

[3] J.Wang, J.Lu, S.B.Hocevar, P.A.M.Farias, Bismuth-Coated Carbon Electrodes for Anodic Stripping Voltammetry, Analytical Chemistry 72(14), 3218-3222(2000); doi: 10.1021/ac000108x

[4] X.Xie, D.Stueben, Z.Berner, The Application of Microelectrodes for the Measurements of Trace Metals in Water, Analytical Letters 38, 2281-2300 (2005); doi: 10.1080/ 00032710500316050

[5] W.Moujahid, P.E.Daly, J.Strutwolf, V.I.Ogurtsov, G.Herzog, D.W.M.Arrigan, Microelectrochemical Systems on Silicon Chips for the Detection of Pollutants in Seawater, Electroanalysis 23(1), 147155(2011); doi: 10.1002/elan.201000424

[6] H.J.Lee, C.Beriet. R.Ferrigno, H.H.Girault, Cyclic Voltammetry at a Regular Microdisc Electrode Array, Journal of Electroanalytical Chemistry 502, 138-145(2001); doi: 10.1016/S00220728(01)00343-6 